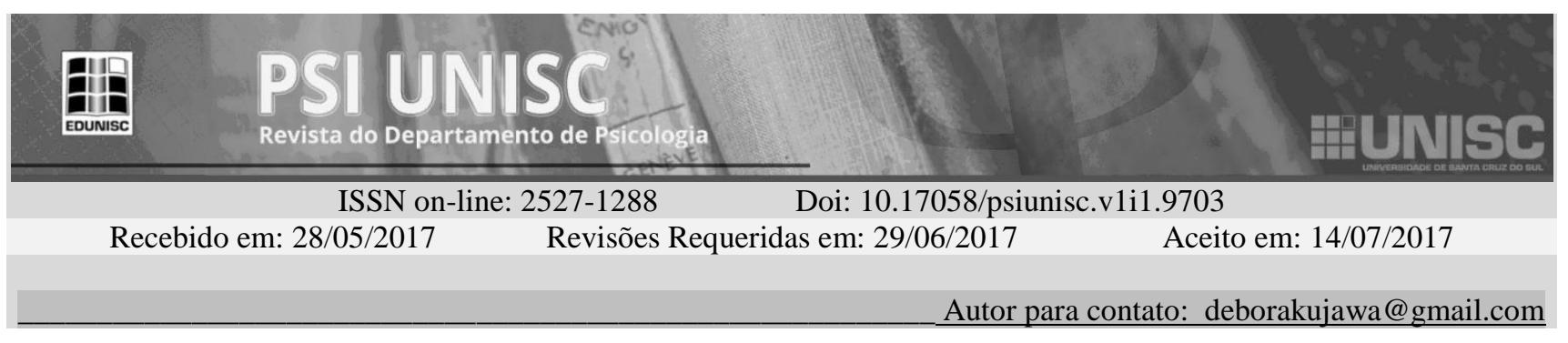

\title{
Inclusão de alunos com necessidade de atendimento educacional especializado: Percepção dos professores
}

\begin{abstract}
Inclusión de alumnos con necesidad de atención educativa especializada: Percepción de los profesores
\end{abstract}

Inclusion of students with special educational needs: Perception of teachers

Débora Rita Kujawa

Faculdade Meridional - Rio Grande do Sul-Brasil

Denice Bortolin

Faculdade Meridional - Rio Grande do Sul-Brasil

Naiana Dapieve Patias

Faculdade Meridional - Rio Grande do Sul - Brasil

\begin{abstract}
RESUMO
O presente trabalho objetivou conhecer a percepção dos professores sobre a inclusão de alunos deficientes em classe regular de ensino. Participaram do estudo, seis professores, com idades entre 24 a 42 anos, de uma escola privada que tinham, pelo menos, um aluno de Educação Especial Inclusiva em sua classe. O estudo é qualitativo, de cunho exploratório e transversal. Foram utilizadas entrevistas semiestruturadas e grupo focal. Análise de conteúdo indicou que, na percepção das professoras, a inclusão é positiva, pois traz benefícios para a criança com deficiência e para os colegas do aluno incluído. No entanto, as mesmas relatam dificuldades relacionadas à compreensão da família sobre o processo de inclusão e a falta de subsídios formativos para realizar a inclusão.
\end{abstract}

Palavras-chave: Alunos. Professores. Inclusão Escolar.

\section{RESUMEN}

El presente trabajo tuvo como objetivo conocer la percepción de los profesores sobre la inclusión de alumnos discapacitados en clase regular de enseñanza. Participaron del estudio, seis profesores, con edades entre 24 y 42 años, de una escuela privada que tenían al menos un alumno de Educación Especial Inclusiva en su clase. El estudio es cualitativo, de cuño exploratorio y transversal. Se utilizaron entrevistas semiestructuradas y grupo focal. El análisis de contenido indicó que, en la percepción de las profesoras, la inclusión es positiva, pues trae beneficios para el niño con 
discapacidad y para los compañeros del alumno incluido. Sin embargo, las mismas relatan dificultades relacionadas con la comprensión de la familia sobre el proceso de inclusión y la falta de subsidios formativos para realizar la inclusión.

Palabras clave: Alumnos. Profesores. Inclusión Escolar.

\begin{abstract}
This work examines teacher's perception about the inclusion of disabled students in the regular classroom Participated in the study, six teachers, aged 24 to 42 years, a private school that had at least one special education student inclusive in its class. The study is qualitative, exploratory and transversal. Semistructured interviews and focus groups were used. Content analysis indicated that, in the teachers' perception, the inclusion is positive, since it brings benefits to the disabled child and to the included student's colleagues. However, they report difficulties related to the family's understanding of the inclusion process and the lack of training subsidies for inclusion.
\end{abstract}

Keywords: Students. Teachers. School inclusion.

\section{Introdução}

A Lei $\mathrm{n}^{\circ}$ 13.146, de 06 de julho de 2015, última publicação que institui a inclusão da pessoa com deficiência, assegura o direito à educação em todos os níveis e aprendizado, por meio dos subsídios que possibilitem o desenvolvimento máximo de seus talentos e habilidades físicas, sensoriais, intelectuais e sociais, em conformidade com suas características, interesses e necessidades de aprendizagem, sendo dever do estado, da família da comunidade escolar e da sociedade. Desta forma, a lei assegura o direito à educação de qualidade e proteção de qualquer forma de violência, negligência e discriminação (Brasil, 2015). Fundamentado em referências epistemológicas, teóricas e metodológicas, o processo de inclusão escolar produz, ainda, muitas dúvidas relacionadas aos encaminhamentos e condutas adequadas para a efetivação da inclusão daquelas crianças que "fogem" dos moldes tradicionais previstos em termos de educação, mesmo com a instituição de leis e regulamentações (Sesti, 2009). Por outro lado, especialistas têm enfatizado que um dos caminhos para a escola aprimorar este processo pode ser dar por meio dos professores, uma vez que estes são a peça chave na implementação da educação inclusiva, pois exercem papel significativo no aprendizado do aluno. Para isso, faz-se necessário dispor de cursos de formação contínuos e permanentes, que garantam aos professores competências essenciais para atuar com as crianças com deficiência (Biaggio, 2007).

Para alguns especialistas, garantir o acesso dos alunos com deficiência em escolas regulares, oferecendo todas as condições de acessibilidade, é imprescindível para a cidadania destas pessoas, pois possibilita o preparo para a inserção nos espaços sociais. Essa tese vai ao encontro da concepção do grande teórico da psicologia chamado Lev S. Vygotsky (1997) o qual dedicou boa parte de sua vida e sua obra à educação das crianças com deficiência e a compreensão dos problemas relacionados à inclusão.

Na perspectiva de Vygotsky ${ }^{1}$ (1997), a deficiência do sujeito não constitui um impedimento para seu desenvolvimento. O que pode causar impedimentos ao seu desenvolvimento são as limitadas restrições que a sociedade coloca sobre o sujeito, ou seja, é a forma como se lida com o problema, negando possibilidades de trocas e relações 
significativas que proporcionem o crescimento do sujeito.

Vygotsky (1997), afirma que a inteligência não é inata, mas uma construção a partir das trocas constantes com o meio ambiente. Esta concepção é sintetizada em seu conceito de Zona de Desenvolvimento Proximal (ZDP) ${ }^{2}$, que desenvolveu por meio de experiências com crianças deficientes mentais. Este conceito indica que, com o auxílio do outro (adulto, colegas mais experientes, professores), o sujeito terá capacidade de produzir além do que consegue produzir sozinho, ou seja, ele tem um potencial para as suas possibilidades que não se realizaram, mas que podem se realizar por intermédio da família, da escola, da comunidade e seus elementos constituintes: pais, irmãos, amigos, colegas e professores (Costa, 2006). Vygotsky (2001) observou que o sujeito deficiente cria situações de aprendizagem diferenciadas quando trabalha em grupos, visto que um auxilia o outro.

Ao compreender que a escola e seus componentes objetivam auxiliar o aluno na aquisição de habilidades, desenvolvimento cognitivo e conhecimentos que lhe permitam viver em sociedade de modo independente, os serviços de apoio devem se modificar para constituírem subsídios efetivos à classe comum. Os serviços de apoio são essenciais no processo de escolarização de alunos que necessitam de atendimento de educacional especializado visto que a formação de professores, seja a do generalista ou do especialista, não tem dado conta das demandas atuais da educação, especificamente 0 da inclusão, entendida como um dos desafios da escola atual (Pinola \& Del Prette, 2014).

A Declaração de Salamanca (1994) destaca que a educação de crianças com deficiência deve ser tarefa desenvolvida em conjunto por pais e profissionais, sejam eles professores, funcionários, etc. Desta forma, a inclusão não pode ser tomada como responsabilidade unicamente do professor, entretanto, não se pode desconsiderar que este é o principal responsável. Nessa perspectiva, o empenho do mesmo na busca pela resolução dos problemas que se colocam em sua prática interfere no desenvolvimento do aluno com deficiência. Assim, o sucesso ou o insucesso da inclusão dependerá significativamente das atitudes e crenças dos professores (Camisão, 2004).

Nesse sentido, é necessário compreender a vivência do professor no processo de inclusão para poder identificar suas necessidades e investir na sua formação. Portanto, entender suas percepções e vivências sobre os alunos com deficiência, verificar os preconceitos que existem e conscientizá-los sobre seu papel na inclusão, são aspectos fundamentais para o processo de desenvolvimento educacional absoluto destes alunos (Barbosa \& Souza, 2010).

Considerando os professores como membros principais no processo de inclusão, as mudanças devem ser planejadas juntamente com eles. Para Mantoan (2006), é fundamental resgatar a confiança para que saibam lidar e desenvolver o processo de ensinoaprendizagem com todos os alunos. Para isso, faz-se necessário proporcionar aos docentes a participação em cursos que discutam estratégias educacionais visando à participação ativa e conscienciosa de todos os alunos. Esses cursos devem atender as carências de preparo que os professores têm para desenvolver práticas docentes que sejam, de fato, inclusivas.

Diante do exposto, este trabalho teve como objetivo geral conhecer a percepção dos professores sobre a inclusão de alunos deficientes em classe regular de ensino. Como objetivos específicos, buscou-se vislumbrar o papel desempenhado pelo professor como agente principal de inclusão especial, compreender como está recebendo formação para o atendimento de alunos com deficiência e entender quais as dificuldades que enfrenta com o processo formativo e as principais necessidades nesta função. 


\section{Método}

Pesquisa qualitativa, transversal e de cunho exploratório.

\section{Participantes}

As participantes da pesquisa foram seis professoras, com idades entre 24 a 42 anos, de uma escola privada, de uma cidade localizada no norte do Estado do Rio Grande do Sul, com tempo de atuação mínima de dois anos. A escola foi escolhida por conveniência, a partir da rede de contatos da pesquisadora (Sampiere, Collado, \& Lucio, 2013). Já o critério de seleção das participantes, deu-se por exaustão (Fontanella, Luchesi, Saidel, Ricas, Turato, \& Melo, 2011), ou seja, foram incluídas todas as professoras da escola que possuíam, pelo menos, um aluno deficiente incluído em sua turma.

\section{Instrumentos}

Para a realização desta pesquisa utilizaram-se dois instrumentos: o grupo focal e a entrevista semiestruturada. O primeiro, é uma técnica qualitativa que propõe a discussão ou o debate de determinada temática com o objetivo de aprofundar o saber, buscando uma pluralidade de ideias. Dias (2000), descreve que o objetivo central do instrumento é identificar sentimentos, atitudes, percepções e produto ou atividade e os objetivos específicos variam conforme a abordagem da pesquisa, neste caso, por se tratar de uma pesquisa exploratória, este teve como objetivo gerar novas ideias ou hipóteses e estimular o pensamento do pesquisador. Sendo assim, os resultados do grupo focal, que foi o ponto inicial da pesquisa, serviram de base para a elaboração conclusiva das perguntas que foram, posteriormente, utilizadas na entrevista semiestruturada individual.

Primeiramente, todas as professoras fizeram parte de um grupo focal. Neste encontro, a proposta foi a discussão de uma cena do filme relacionado à inclusão ("Como estrelas na Terra, toda criança é especial”), com o intuito de explorar o ponto de vista do professor sobre o processo de inclusão, quais as dificuldades enfrentadas e quais as melhorias a serem implantadas. A discussão teve duração de 1 hora e 30 minutos, foi gravada e transcrita na íntegra.

O segundo instrumento utilizado foi as entrevistas semiestruturadas, uma estratégia de pesquisa importante para subsidiar uma pesquisa ou uma ação, é o método mais utilizado no processo de trabalho de campo. Galliano (1986) descreve como um processo de interação que articula quatro eixos em conjunto: entrevistador, entrevistado, situação da entrevista e roteiro da entrevista. Esse método possibilita a obtenção de informações qualitativas sobre um estudo.

A entrevista semiestruturada individual, constituiu-se por 15 questões abertas que abordaram o ponto de vista das professoras sobre o processo de inclusão, suas dificuldades enfrentadas para a realização desta prática; os subsídios que recebem para desenvolver tal atividade e as estratégias e metodologias que podem trazer melhorias a este processo. Cada entrevista durou, aproximadamente, 30 minutos.

\section{Procedimentos}

Mediante a autorização da escola, o projeto foi submetido e aprovado pelo Comitê de Ética da Faculdade Meridional - IMED. Após a aprovação pelo CEP, a pesquisadora foi novamente até a escola para uma reunião com a coordenadora pedagógica e a orientadora educacional com o objetivo de convidar os professores que trabalhavam em turmas que possuíam alunos com deficiência incluídos e foi agendado o grupo focal com estas profissionais, mediante seu consentimento e interesse em participar da pesquisa.

Em um segundo momento com a escola foi realizado o grupo focal, com a participação de todos os professores selecionados para a pesquisa. Inicialmente, a 
pesquisadora se apresentou, explicou o objetivo do estudo e os objetivos do encontro, a voluntariedade da participação, bem como o sigilo e a possibilidade de desistir da pesquisa em qualquer momento sem prejuízo. Todas as participantes assinaram o Termo de Consentimento e Livre Esclarecimento (TCLE). Posterior ao encontro foram marcados dias e horários para as entrevistas individuais.

\section{Análise dos dados}

Após as gravações e transcrições das entrevistas e do grupo focal, os dados foram submetidos à análise de conteúdo. Esse método refere-se a um conjunto de técnicas para análise das comunicações através de procedimentos sistemáticos e objetivos de descrição do conteúdo dos dados coletados. A técnica pretende analisar, principalmente, as falas e as informações coletadas, de forma extensiva e ocorre através de três momentos: pré-análise, exploração do material e interpretação dos dados (Bardin, 1977). Em um primeiro momento houve a organização do material, ou seja, transcrição das entrevistas e da discussão do encontro. Após isso, foi realizada leitura exaustiva das transcrições, a partir das questões e objetivos do estudo, organizando a descrição das falas e sua interpretação a partir de estudos sociais e culturais relacionados ao tema.

\section{Resultados e discussões}

A seguir será apresentada uma tabela demonstrativa com fragmentos das respostas obtidas durante as entrevistas.

Tabela 1 percepções sobre o processo de inclusão

\section{Participante Idade Formação/ $\quad$ Recortes das falas das entrevistas e do grupo focal Tempo}

Eu acho que a inclusão deve ser trabalhada para que os alunos "normais" aceitem os "diferentes", aceitem as "diferenças", o professor precisa primeiro trabalhar o todo da "aceitação"

Maria

37

anos

Graduada em

para que os alunos "normais" não tratem o colega como uma

Letras há 18
anos

pessoa estranha [...] Eu acho que os alunos que não são da inclusão aprendem muito com o aluno da inclusão, porque eles aprendem a respeitar, a ajudar, aprendem a serem mais participativos, mais humildes, a ver que o colega precisa de ajuda e se dispor a ajuda".

Eu acho que sempre que tem uma criança com necessidade de educação especial dentro de uma sala de aula, ela vem a contribuir muito com o crescimento de todos, [...] e segundo porque o olhar do professor passar a ser um olhar que sai do

$\begin{array}{lll}\text { Julia } & 42 & \begin{array}{l}\text { Graduada em } \\ \text { Pedagogia há } \\ \text { anos }\end{array} \\ & 20 \text { anos }\end{array}$
genérico e passa a olhar para o específico [...] existem muitos ganhos, lógico desde que haja vontade do professor em querer fazer diferença com o aluno em sala de aula, haja comprometimento dele em trazer a turma para este contexto e haja disponibilidade e entendimento dos pais da criança que está sendo incluída também que esse processo é um processo lento e que tudo vai acontecer dentro das suas características 


\begin{tabular}{|c|c|c|c|}
\hline Isabel & $\begin{array}{l}33 \\
\text { anos }\end{array}$ & $\begin{array}{l}\text { Graduada em } \\
\text { Pedagogia há } \\
6 \text { anos }\end{array}$ & $\begin{array}{l}\text { A inclusão tem dois lados da moeda, por um lado é bom, mas } \\
\text { por outro lado você tem que dar uma atenção a mais para o } \\
\text { aluno, porque devido a deficiência dele você tem que prender } \\
\text { mais ao lado dele, dar mais atenção [...] E o lado bom é no } \\
\text { processo de socialização, o relacionamento com os colegas é } \\
\text { tranquilo, as vezes tem que fazer a mediação [...]. }\end{array}$ \\
\hline Alice & $\begin{array}{l}28 \\
\text { anos }\end{array}$ & $\begin{array}{l}\text { Graduada em } \\
\text { Pedagogia há } \\
6 \text { anos }\end{array}$ & $\begin{array}{l}\text { Acredito que os alunos da turma em geral têm benefícios com o } \\
\text { processo da inclusão pelo fato de conhecer "o outro", de } \\
\text { respeitar o colega com necessidades especiais [...]. Mas } \\
\text { também tem o lado do professor, este tem que fazer um } \\
\text { planejamento de atividades de acordo com as limitações do } \\
\text { aluno, senão pode acarretar prejuízos para este aluno e para os } \\
\text { demais da classe. }\end{array}$ \\
\hline Vera & $\begin{array}{l}24 \\
\text { anos }\end{array}$ & $\begin{array}{l}\text { Graduada em } \\
\text { Pedagogia há } \\
2 \text { anos }\end{array}$ & $\begin{array}{l}\text { Eu sou muito a favor da inclusão, ela traz muitos benefícios, é } \\
\text { muito positiva não só para o aluno incluído como também para } \\
\text { os demais da classe, eu vejo na minha turma como eles tem } \\
\text { mais respeito, são mais solícitos com o colega com NEE, } \\
\text { envolve também questões familiares, algumas famílias não } \\
\text { aceitam no início, mas no decorrer do processo da inclusão } \\
\text { sensibiliza e valoriza muita coisa de cultura. }\end{array}$ \\
\hline Joana & $\begin{array}{l}41 \\
\text { anos }\end{array}$ & $\begin{array}{l}\text { Graduada em } \\
\text { Pedagogia há } \\
10 \text { anos }\end{array}$ & $\begin{array}{l}\text { Acredito que conforme o grau da deficiência e os sintomas que } \\
\text { apresenta, é que começam as dificuldades, quando mais } \\
\text { agravante sejam estes sintomas ou esse processo, será mais } \\
\text { difícil tanto para o aluno ali inserido como para os demais } \\
\text { colegas e também professores, porque administrar uma coisa } \\
\text { que não é "normal" do comportamento digamos assim, eles } \\
\text { reagem de uma forma diferente, então o maior desafio seria } \\
\text { encontrar maneiras para que isso fique mais comum. }\end{array}$ \\
\hline
\end{tabular}

Fonte: Dados da pesquisa.

Ao analisar as respostas de cada participante nas questões, encontram-se semelhanças e diferenças no conteúdo das falas; sendo assim, estas serão destacadas no decorrer desta análise. Ao questionar as professoras acerca das percepções que têm sobre o processo de inclusão, a maioria destaca que concebe a inclusão como algo positivo e que traz benefícios para a criança com deficiência, principalmente para os colegas do aluno incluído. Este conteúdo foi expresso por Maria na fala "os alunos que não são da inclusão aprendem muito com o aluno da inclusão, porque eles aprendem a respeitar, ajudar, a serem mais participativos, mais humildes e a ver que o colega precisa de ajuda e se dispõe a ajudar".

A fala da professora descrita acima refere aspectos contemplados pela perspectiva de Vygotsky (1998) ao referir-se que o desenvolvimento cognitivo é formado pela interação do sujeito com o meio social, pois na troca de experiência com os sujeitos é possível adquirir conhecimentos, papéis e funções sociais que permitem apropriar-se de conhecimentos para a formação da consciência. Nesse sentido, compreende-se que a inserção dos alunos com deficiência no meio social é necessária para o desenvolvimento cognitivo; sendo assim, 
utilizando-se esse mesmo raciocínio, pode-se concluir que os alunos "normais" aprendem muito com os alunos com deficiência, principalmente aspectos relacionados às interações sociais.

Outra fala, referida pela professora Júlia, também indica os benefícios da inclusão, embora a mesma sugira alguns fatores que contribuem para que o processo seja efetivo. "Existem muitos ganhos, lógico desde que haja vontade do professor em querer fazer diferença com o aluno em sala de aula, haja comprometimento dele em trazer a turma para este contexto e haja disponibilidade $e$ entendimento dos pais da criança que está sendo incluída também que esse processo é um processo lento e que tudo vai acontecer dentro das suas características".

A fala da professora Julia vai encontro aos achados na literatura. Vygotsky (1997) discorre que a pessoa que transmite o processo de ensino pode facilitar ou dificultar o aprendizado. O educador, no processo de ensino, deve produzir avanços nos alunos, já que o mesmo não é somente um sujeito da aprendizagem, mas é também aquele que aprende junto com o outro o que os homens já realizaram historicamente. Assim, o desenvolvimento cognitivo se forma por intermédio do outro e há uma perspectiva, mas esta não foge das regras do desenvolvimento da criança "normal", apenas deve-se considerar que o tempo gasto para tal é diferente, é mais lento, ou seja, a criança especial pode avançar tanto quanto àquela "normal", a diferença está na formação dos processos superiores, isto é, ela se desenvolve de forma diferente. Desta forma, ao considerar que qualquer insuficiência muda a relação do sujeito deficiente com o mundo, interferindo nas relações sociais que o mesmo constitui, é imprescindível a compreensão dos pais sobre o tempo que seu filho necessita para desenvolver-se, para que não ocorram interferência nas relações dele com o outro.

Vygotsky (1997) afirma que o sujeito aprende através da interação social com o outro, assim, pode-se conceber a família como uma agente promotora deste processo, na medida que, a primeira relação social que a criança experimenta é no ambiente familiar. Ao partir deste pressuposto, compreende-se que o sujeito com deficiência desenvolverá inúmeras habilidades neste ambiente, assim como este também pode influenciar na sua construção de habilidades. Contudo, percebese que a família ainda possui dificuldades para compreender que o sujeito com deficiência tem um tempo diferente por conta das suas características e que, por consequência, seu desenvolvimento é mais lento. Talvez a família desenvolva esta habilidade somente quando seu filho for incluído; por isso, é importante chamar a atenção para este fator, porque muitas vezes os pais não têm clareza sobre ocorre o processo e como devem conduzir, assim como também a escola não percebe que, além de incluir o aluno, deve auxiliar a família neste processo.

De acordo com Reis (2012), a escola, como uma instituição social, deve primar pela busca de mecanismos que proporcionam um trabalho avançado em favor da mobilização dos membros da escola e da família, em direção de maiores respostas aos desafios que impõe a inclusão.

\section{Sendo a educação pré-escolar complementar da ação educativa da família, haverá que assegurar a articulação entre o estabelecimento educativo e as famílias, no sentido de encontrar, num determinado contexto social, as respostas mais adequadas para as crianças e famílias, cabendo aos pais participar na elaboração do projeto educativo do estabelecimento. (Ministério da Educação [MEC], 2002, pp. 22-23).}

Portanto, é papel da escola, promover o envolvimento da família nas ações dos projetos educativos e pedagógicos para melhorar a posição da família no processo educativo do seu filho. Mais do que criar um espaço para tratar destas questões com a 
família, escola, a própria escola deve articular os seus recursos institucionais, visando assegurar que as reflexões, os debates, as propostas, etc. possam proporcionar o desenvolvimento social por meio de práticas pedagógicas educativas eficientes (Reis, 2012).

Ainda sobre as percepções do processo da inclusão de alunos com deficiência, as professoras Julia, Isabel e Alice acrescentam que um dos fatores que fundamenta a inclusão é o envolvimento do professor. A responsabilidade maior está nele, pois é quem desenvolverá a prática, e por isso tem que dar mais atenção ao aluno com deficiência, ou seja, planejar atividades de acordo com as limitações, para não trazer prejuízos. Em função disso, questiona-se: como é realizada a inclusão do aluno com deficiência? A professora Joana explica que, "eu busco primeiro o planejamento, busco estratégias para deixar mais confortável possível". É importante ainda destacar a fala da Julia: "o primeiro passo é fazer o plano individualizado da criança, se tem profissionais que atendem ela, como psicóloga, fonoaudióloga, terapeuta ocupacional. Sento com eles elou com os pais e pensamos junto o que é importante para a criança naquele momento, quais os prérequisitos que preciso para trabalhar com ele para alcançar conteúdos $X$ (...).

Pode-se relacionar as falas das participantes acima, Joana e Julia, com o argumento de Vygotsky (1997), quando diz que não é necessária nenhuma teoria específica para trabalhar com o aluno deficiente, basta compreender e propor intervenções de desenvolvimento para esses sujeitos. Todos aprendem e se desenvolvem, até aqueles com deficiência mais grave, desde que sejam compensados com ensino apropriado, pois o aprendizado organizado adequadamente traz resultados para $o$ desenvolvimento mental. Diante disso, entende-se que é necessário compreender a criança para pensar nas intervenções. Esta conversa com os profissionais envolvidos e/ou com os pais, como destaca Julia, possibilita a compreensão para planejar as intervenções adequadas. Portanto, observa-se que as professoras estão engajadas e preocupadas com a inclusão quando dizem que existe um planejamento das atividades e que propõem ao aluno trabalhos com metodologia diferenciada dos demais, mas com o mesmo conteúdo.

Sobre as características necessárias ao profissional que trabalha com o aluno deficiente, as professoras descrevem a "sensibilidade" como sendo a principal. Julia expõe que, "a principal característica é um olhar diferenciado, se o professor não tiver este olhar sensivel sobre a necessidade do aluno, ele não conseguirá desenvolver um trabalho eficiente (...) nada disso irá funcionar se o olhar dele não for um olhar sensivel, se não conseguir enxergar na criança um ser em potencial (...)". A sensibilidade está associada ao que Alice fala, “(...) o profissional tem que ter uma visão de que o aluno tem potencial (..)".

Chama-se a atenção para a característica citada acima porque em sua teoria Vygotsky defende que para compreender o desenvolvimento humano, não devemos considerar somente o desenvolvimento real da criança, ou seja, aquilo que a criança já tem capacidade de fazer sozinha, como também o seu nível de desenvolvimento potencial, capacidade de desempenhar tarefas com a ajuda dos mais experientes. Ainda, em seus estudos, defende que "a tese central da defectologia atual é a seguinte: todo defeito cria os estímulos para elaborar uma compensação" (Vygotsky, 1997, p. 14). A partir desta consideração parte-se do pressuposto que o estudo da criança com deficiência não pode limitar-se à determinação do nível ou grau de insuficiência, tem que incluir processos compensatórios. É fundamental que o professor olhe para o aluno como um ser em potencial, que não alcançar o mesmo nível de aprendizagem que os colegas, mas qualquer pequena evolução para ele pode significar uma grande conquista. Assim, o 
profissional deve haver sensibilidade para perceber o que é necessário para desenvolver o potencial e proporcionar oportunidades para o crescimento.

Acerca das dificuldades que encontram no processo de inclusão do aluno com deficiência Maria destaca que: "a principal dificuldade é aceitação dos outros, primeiro o professor tem que se despir de qualquer preconceito ou pré-conceito da inclusão, tem que preparar as outras crianças ao diferente (...) tem que preparar o ambiente para receber o aluno da inclusão e as vezes não temos todos os subsídios". Joana também coloca que a maior dificuldade é "não pensar neste aluno antes de conhecer, criar um pré-conceito dele antes de conhecê-lo, acho que é a pior parte". A respeito disso, Barbosa e Souza (2010), entendem que estas crenças são consequências das representações que foram construídas ao longo da história sobre as crianças com deficiência, tendo como base rótulos e estigmas. Nesse sentido, pode-se pensar que o professor também precisa ser olhado como sujeito que necessita de recursos, de condições especiais para desenvolver o trabalho da inclusão.

Ainda tratando-se das dificuldades, a professora Vera expõe que " $a$ maior dificuldade é não ter um tempo longo de formação, gostaria que fossem oferecidos mais encontros, que os professores pudessem participar de pesquisas, reuniões, conversas com quem tem mais experiência nesta temática. Se a escola não disponibilizar é complicado (...) o professor realmente tem que estar disposto (...)" Vygotsky (1997), diz que o sujeito que conduz o processo de ensino pode possibilitar ou impossibilitar o processo da aprendizagem; por isso, é necessário mudar as práticas pedagógicas de produção e minimização, que dificultam as possibilidades de aprendizagem. $\mathrm{O}$ autor ainda afirma que o objetivo da educação do aluno com deficiência é atingir o mesmo fím da criança "normal", porém utilizando meios diferentes.
De acordo com o que Vera expõe acima, a escola deve disponibilizar estes encontros de formações, de conversa com profissionais experientes, mas destaca que essa não é uma tarefa somente da instituição. É primordial que haja envolvimento e disposição do professor. Compreende-se que é fundamental $\mathrm{o}$ engajamento de todos os envolvidos, ou seja, a escola deve propor, incentivar e garantir momentos de formação e os profissionais devem participar com motivação e engajamento, objetivando uma melhor prática formativa. Outras dificuldades também foram citadas como: maior envolvimento e compreensão da família no processo e obstáculos com relação à realização das atividades. Há também a dúvida sobre qual a melhor metodologia a ser utilizada em cada caso. Estes problemas que dizem respeito à prática metodológica estão estreitamente relacionadas à falta de formação continuada.

Neste contexto, as professoras foram questionadas sobre o que poderia auxiliá-las a trazerem melhorias ao processo de inclusão, Maria coloca que deveria "ter mais atividades práticas, palestras (...) propostas de formação direcionada à prática, exemplos de atividades que posso desenvolver com o aluno, isso é fundamental". De acordo com Soresi (2007), a educação inclusiva se efetiva em ambientes em que o ensino é ativo e participativo, e onde as dificuldades e os problemas que surgem são analisados para produzir melhoramentos. $\mathrm{Ou}$ seja, são necessárias propostas de formação. É importante destacar que praticamente todas as professoras ressaltaram que a escola está preocupada com esta questão, disponibiliza encontros de capacitação, porém, ainda não é suficiente. Entende-se que, para o professor desenvolver as práticas educacionais efetivas, a instituição e a equipe pedagógica devem proporcionar momentos de formações mais participativas, com aspectos mais didáticos que realmente possam auxiliar na execução da prática inclusiva. 
Ainda sobre a formação questionou-se: Qual a sua compreensão conceitual de formação? A professora Alice fala que "formação não depende só de cursos que o profissional busca ou que o colégio propõe, não é só o diploma, formação também é pegar o livro e ler, pesquisar em sites; na própria conversa com outro profissional é possível aprender bastante". Sobre isso, Montoan (1997), ressalta que os professores esperam que a formação garanta $o$ preparo que necessitam para atender todos os alunos; porém, recebem a capacitação como sendo mais um curso que certificará e convalidará a capacidade de desenvolver a inclusão.

Diante do conceito de formação exposto acima por Alice, vale ressaltar que não somente na fala dela, mas também das outras participantes aparece, com destaque, o verbo "buscar". Isso significa que elas se colocam em uma posição ativa. Entendem que todo e qualquer preparo deve partir da vontade e iniciativa pessoal; desta forma, entende-se que esta postura é tomada em função de trabalharem em uma instituição privada. No entanto, apesar das professoras definirem o conceito de formação como uma questão mais voltada para iniciativas pessoais, quando destacam as dificuldades que encontram no processo de inclusão, apontam para dificuldades metodológicas que demandam a necessidade de apoio da escola e da equipe pedagógica, ou seja, elas têm a percepção que devem buscar, mas a escola não pode esperar somente a boa vontade do professor. A escola deve ser o espaço de incentivo, oportunizador e garantidor da formação dos seus profissionais

Sobre aos aspectos que precisam ser trabalhados, Isabel cita "aspectos que me auxiliassem no como agir com o aluno, aspectos mais práticos, atividades que podem ser realizadas com os alunos de tais diagnósticos (...)". Para isso, a professora Maria sugere que "a escola poderia elaborar um núcleo de educação inclusiva, incluindo profissionais que trabalham com alunos incluídos e aqueles que tem experiência, conhecimento sobre a temática, e haverem encontros mensais, quinzenais para trocar experiências, com a troca de experiência se aprende muito. A escola deve propor um trabalho com nós professores em longo prazo, trabalho continuo e com encontros mais seguido".

Isabel destaca que "pode ser trabalhado através de exemplos, exemplos de atividades, enfim, troca de experiências são fundamentais", e a Alice também ressalta que é possível trabalhar estes aspectos práticos "trazendo exemplos, através de estudos de casos, é possível visualizar a prática". Montoan (1997) enfatiza que os professores introjetam o papel de praticantes e esperam que a formação ensine o que é preciso fazer, acreditam que os conhecimentos que lhes faltam para ensinar as crianças com deficiências referem-se à conceituação, etiologia, prognósticos das deficiências e que necessitam conhecer e saber questões mais práticas, como aplicar métodos e técnicas específicas para a aprendizagem destes alunos. Observa-se que as professoras destacam a falta de formação de aspectos práticos, concretos, por isso sugerem grupos de estudos, encontros para troca de experiências, estudos de casos, etc. Portanto, é preciso continuar investindo na capacitação e ficar atento em como os capacitados aprendem para realizar e aperfeiçoar as práticas inclusivas.

\section{Considerações Finais}

Este estudo teve como objetivo geral, conhecer a percepção dos professores sobre a inclusão de alunos deficientes em classe regular de ensino. Para além do objetivo, oportunizou um conhecimento do cenário atual da Educação Especial Inclusiva em uma instituição de ensino privado, além do conhecimento das práticas desenvolvidas pelos professores e os subsídios formativos que recebem para desenvolver esta prática. $\mathrm{O}$ presente trabalho também proporcionou a compreensão das dificuldades que os esses 
profissionais enfrentam no processo de inclusão dos alunos com deficiência.

Foi possível evidenciar que as participantes trouxeram considerações muito semelhantes. Todas as professoras entrevistadas concebem o processo de inclusão dos alunos com deficiência como positivo, principalmente pelo aprendizado que os colegas "normais" adquirem com os colegas "especiais". Mas, ao mesmo tempo, elas compreendem que, para haver benefícios, dependerá do engajamento dos professores, além da colaboração e participação dos pais.

Portanto, percebeu-se que uma das dificuldades encontradas para desenvolver o processo de inclusão de alunos com deficiência é a falta de compreensão e participação da família. $\mathrm{O}$ processo de aprendizagem de crianças deficientes é mais lento e, por vezes, a ansiedade dos pais em querer ver os resultados do filho dificulta o trabalho do profissional na escola. Outro elemento que foi destacado é a falta de subsídios formativos para os professores realizarem a prática da inclusão. Diante disso, foi possível evidenciar que a instituição escolar está envolvida e preocupada com a inclusão destes alunos, está propondo momentos de encontros e palestras sobre esta temática, contudo parece que ainda não atende a demanda das professoras, não ocorrem formações com frequência para auxiliá-las na execução da prática.

Além disso, é importante também destacar o relato de duas educadoras a respeito das dificuldades. Para elas, a principal dificuldade é a aceitação do "outro" em relação ao aluno com deficiência. Sendo assim, o professor deve exercer um papel de mediador, buscando preparar o ambiente e os alunos "normais" para receber o aluno especial, neste caso, observa-se que além de fazer esta mediação com os colegas, de prepará-los para o recebimento do aluno deficiente, ele também pode ter concepções e crenças próprias a respeito do aluno deficiente. Portanto, percebe-se que o professor necessita muito olhar para si mesmo para trabalhar estas questões internas.

Observou-se, nas falas das participantes, que ao conceituar "formação" surge uma posição contraditória. Todas definiram "formação" utilizando o verbo "buscar". Formação é uma questão de iniciativa pessoal. Porém, ao falarem de superação das dificuldades destacam, na prática, que isto demanda apoio do colégio e da equipe pedagógica. A partir disso, compreende-se que esta contradição pode ser justificada por tratar-se de uma instituição privada, em que os educadores se colocam em uma posição ativa, devem ter iniciativa própria e ir em busca de subsídios para desenvolverem seu trabalho. Contudo, não se pode desconsiderar a escola como um espaço de incentivo e oportunidades de formação aos professores.

Para atender as demandas apontadas pelas participantes, considerando a iniciativa pessoal dos professores e a escola como oportunizadora do espaço, sugere-se uma intervenção. Desta forma, é relevante que a escola disponibilize espaço para criar um grupo de apoio, com a finalidade de oportunizar aos profissionais que trabalham com os alunos com deficiência troca de experiências, discussão de textos teóricos e estudos de casos. Sugere-se também que estes encontros possam ser mais frequentes, uma vez que, conforme salientado por duas participantes, as dúvidas do professor surgem no decorrer do processo, por isso se os momentos de formação fossem mais frequentes como por exemplo, mensais, ele teria mais subsídios formativos.

Portanto, estes encontros objetivam auxiliar o professor nos aspectos práticos da inclusão, por meio de troca de experiências e estudos de casos, com o relato de cada participante. Pode-se pensar também na participação de um psicólogo, com o propósito de centralizar um olhar voltado aos profissionais, pois a inclusão demanda muito cuidado emocional que, por vezes, pode causar 
sofrimento no trabalho e sentimento de impotência.

Além do processo formativo com os profissionais, foi ressaltada a importância da compreensão e participação da família. Sugere-se que instituição também tenha um olhar voltado as famílias das crianças com deficiência. É importante que a equipe pedagógica e o professor envolvido unam-se à família para traçar o que os pais esperam e até onde a criança pode ir, para evitar a ansiedade e frustração da família. Ainda, pode-se pensar em ciclos de palestras e outras atividades de cunho formativo, que possam ser realizadas com os pais.

Por fim, à luz das considerações apresentadas, é possível observar que o processo de inclusão de alunos com deficiência ainda tem um bom caminho a ser trilhado. Como se pode perceber neste estudo, os professores estão recebendo formação, mas ainda não é suficiente, visto ser necessário um processo de ensino-aprendizagem constante, já que, além da formação, cabe o olhar sensível do profissional que deve compreender os sujeitos com os quais está atendendo e a vontade de fazer diferente. O limite desta pesquisa foi atender aos objetivos pelo viés dos professores. Contudo, sugere-se que sejam realizados estudos envolvendo também as famílias destas crianças, pois os profissionais demonstraram dificuldades no seu trabalho em decorrência da falta de compreensão e de participação da família.

\section{Referências}

Barbosa, E. T., \& Souza, V. L. T. de. (2010). A Vivência de professores sobre o processo de inclusão: um Estudo da perspectiva da psicologia Histórico - Cultural. Rev. Psicopedagogia, 27(84): 352-62.

Biaggio, Rita de. (2007). A inclusão de crianças com deficiência cresce e muda a prática das creches e pré - escolas. Revista Criança, Brasília, 44, 19-26.

Brasil.. Presidência da República. (2015). Lei 13.146, de 6 de julho de 2015. Institui a Lei
Brasileira de Inclusão da Pessoa com Deficiência (Estatuto da Pessoa com Deficiência).

Costa, D. A. F. (2006). Superando Limites: A Contribuição de Vygotsky para a Educação Especial. Revista de Psicopedagogia. 23(72), 232-240.

Declaração de Salamanca. (1994). Necessidades educativas especiais- NEE. In: Conferência Mundial sobre NEE: Qualidade- UNESCO. Salamanca/Espanha: UNESCO.

Dias, C. A. (2000). Grupo Focal: técnica de coleta de dados em pesquisas qualitativas. Revista Informação \& Sociedade: Estudos, 10(2), Universidade Federal da Paraíba.

Fontanella, B. J., Luchesi, B., Saidel, M., Ricas, J., Turato, E., \& Melo, D. (2011). Amostragem em pesquisas qualitativas: Proposta de procedimentos para constatar saturação teórica. Cadernos de Saúde Pública, 27(2), 389-394.

Mantoan, M. T. E. (2006). Igualdade e diferenças na escola como andar no fio da navalha. Educação (PUC/RS), 1(58),55-64.

Ministérioda Educação (2002). Orientações Curriculares para a Educação PréEscolar. Ministério da Educação, Lisboa.

Pinola, A. R. R., \& Del Prette, Z. A. P. (2014). Inclusão Escolar, Formação de Professores e a Assessoria Baseada em Habilidades Sociais Educativas. Revista Brasileira de Educação Especial, 20(3), 341-356.

Reis, Vânia Alexandra dos Santos. (2012). $O$ envolvimento da família na educação de crianças com necessidades educativas especiais. Dissertação (Mestrado em Ciências da Educação na Especialidade em Domínio Cognitivo-Motor). Escola Superior de Educação João de Lisboa.

Sampieri, R., Collado, C., \& Lucio, M. (2013). Metodologia de pesquisa. Porto Alegre: Penso.

Sesti, R. C. (2009). A Inclusão de Alunos com Funcionamento Psicótico na Escola Regular. Dissertação (Mestrado em Educação). Universidade de Passo FundoUPF. Passo Fundo. 
Soresi, Salvatore. (2007). Psicologia delle Disabilità. Bologna: Mulino.

Vygotsky, L. S. (2001). A construção do pensamento e da linguagem. São Paulo: Martins Fontes.

Vygotsky, L. S. (1998) (6). A Formação Social da Mente: O Desenvolvimento dos Processos Psicológicos Superiores. São Paulo: Martins Fontes.

Vygotsky, L. S. (1997). Fundamentos de defectologia. In: L. S. Vygotsky, Obras escolhidas (Tomo 5), Madri: Visor.

Notas

\footnotetext{
A obra de Lev S. Vygotsky

"Fundamentos de defectologia" traz contribuições muito relevantes a quem estuda e busca compreender o processo de inclusão de alunos com necessidades educativas especiais.

${ }^{2}$ ZDP - A distância entre o nível de desenvolvimento da criança, que é determinada pela capacidade dela na resolução de problemas de forma individual (nível real) e o nível de desenvolvimento potencial, determinado através da resolução de problemas sob orientação de um adulto.
}

Dados sobre as autoras:

- Débora Rita Kujawa é Psicóloga (Faculdade Meridional, IMED), mestranda em Psicologia na Faculdade Meridional IMED.

- Denice Bortolin é Psicóloga, doutoranda em Psicologia Clínica na Universidade do Vale do Rio dos Sinos (UNISINOS). Docente da Faculdade Meridional (IMED, Passo Fundo, $\mathrm{RS})$.

- Naiana Dapieve Patias é Psicóloga, Doutora em Psicologia (UFRGS), Especialista em Psicologia Escolar (CAPE, Porto Alegre-RS).
Docente da Faculdade Meridional (IMED, Passo Fundo, RS). 